Supporting Information

\title{
Selective DNA Recognition and Cytotoxicity of Water Soluble Helical Metallosupramolecular Polymers
}

Utpal Rana,,$^{\dagger}$ Chanchal Chakraborty, ${ }^{\dagger,+}$ Rakesh K. Pandey, ${ }^{\dagger}$ Md. Delwar Hossain, ${ }^{\dagger}$ Reiko Nagano, ${ }^{\S}$ Hiromi Morita, ${ }^{\S}$ Shinya Hattori, ${ }^{\S}$ Takashi Minowa ${ }^{\S}$ and Masayoshi Higuchi $^{*+}$

${ }^{\dagger}$ Electronic Functional Macromolecules Group, National Institute for Materials Science (NIMS), Tsukuba 305-0044, Japan. E-mail: HIGUCHI.Masayoshi@nims.go.jp

${ }^{\dagger}$ International Center for Materials Nanoarchitectonics (MANA), NIMS, Tsukuba 305-0044, Japan

${ }^{\S}$ Nanotechnology Innovation Station, NIMS, 1-2-1 Sengen, Tsukuba 305-0047, Japan

*Corresponding Author; Masayoshi Higuchi. Email: HIGUCHI.Masayoshi@nims.go.jp Tel. \& Fax: +81-29-860-4721 


\section{Contents:}

Figure S1-S4. ${ }^{1} \mathrm{H}$ NMR and ${ }^{13} \mathrm{C}$ NMR spectra of $(\boldsymbol{R})-\mathbf{1}$

Figure S5-S8. ${ }^{1} \mathrm{H}$ NMR and ${ }^{13} \mathrm{C}$ NMR spectra of $(\boldsymbol{S})-\mathbf{1}$

Figure S9-S12. ${ }^{1} \mathrm{H}$ NMR and ${ }^{13} \mathrm{C}$ NMR spectra of $(\boldsymbol{R})-\mathbf{L} 1$.

Figure S13-S16. ${ }^{1} \mathrm{H}$ NMR and ${ }^{13} \mathrm{C}$ NMR spectra of (S)-1.

Figure S17. ${ }^{1} \mathrm{H}-{ }^{1} \mathrm{H}$ COSY NMR spectra of $(\boldsymbol{R})$-L1.

Figure S18. FTIR spectra of (P)-polyFe.

Figure S19. Raman spectra of $(\boldsymbol{P})$-polyFe.

Figure S20. An AFM image of ct-DNA.

Figure S21. Height profile of ct-DNA (B-form)-(P)-polyFe conjugates. 


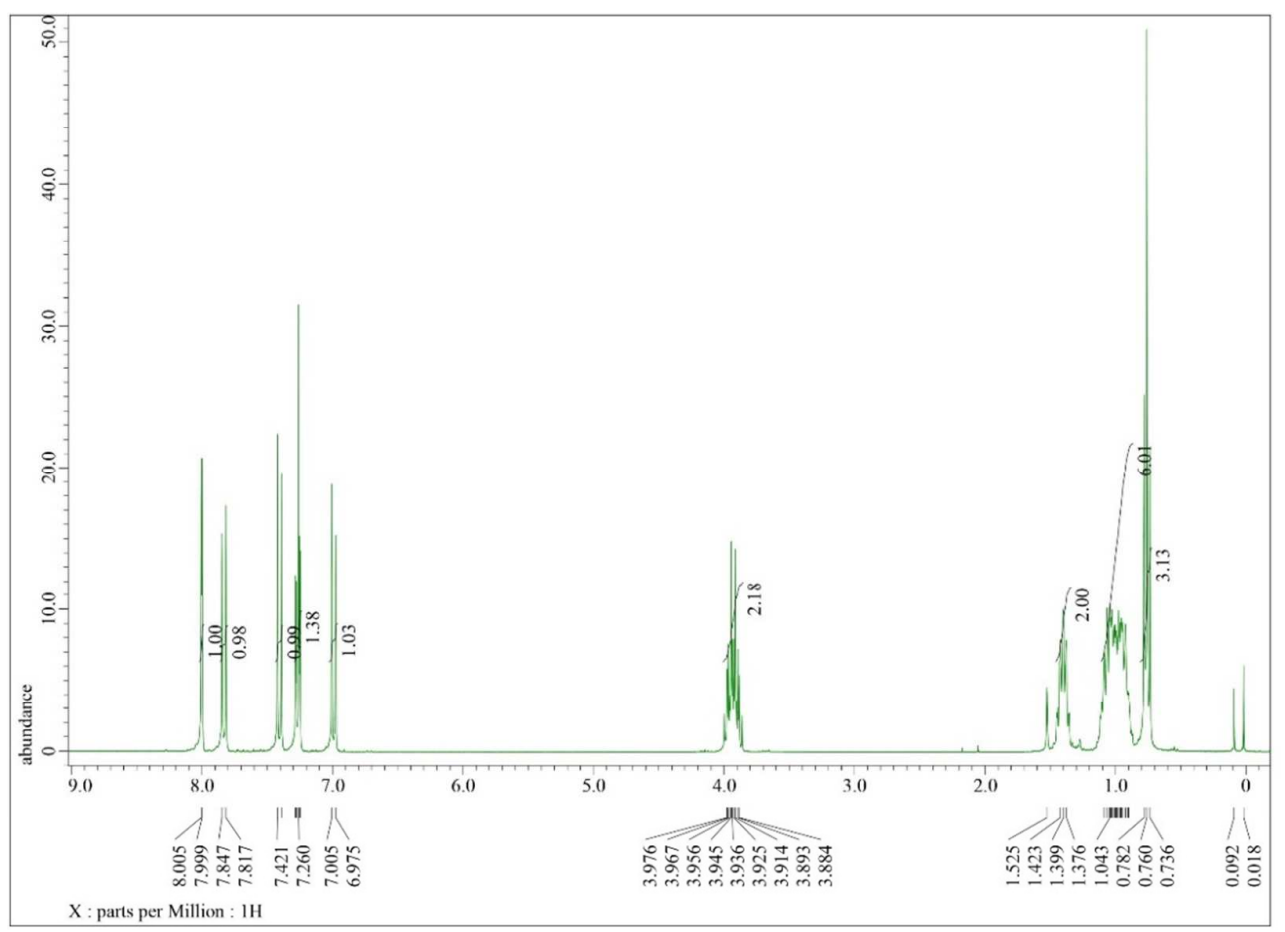

Figure S1. ${ }^{1} \mathrm{H}$ NMR spectra of $(\boldsymbol{R})-\mathbf{1}$ (whole).

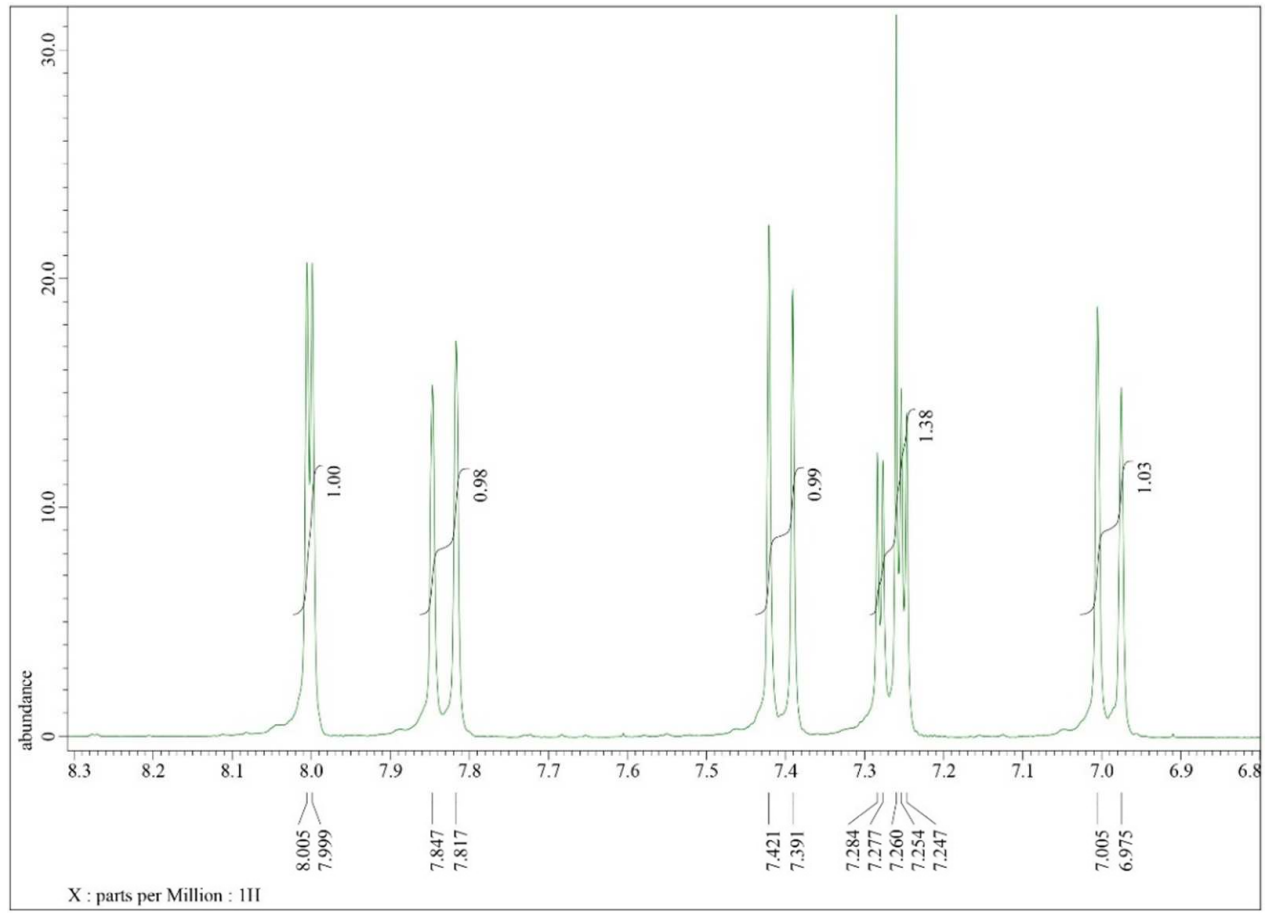

Figure S2. ${ }^{1} \mathrm{H}$ NMR spectra of $(\boldsymbol{R})-\mathbf{1}(8.3-6.8 \mathrm{ppm})$. 


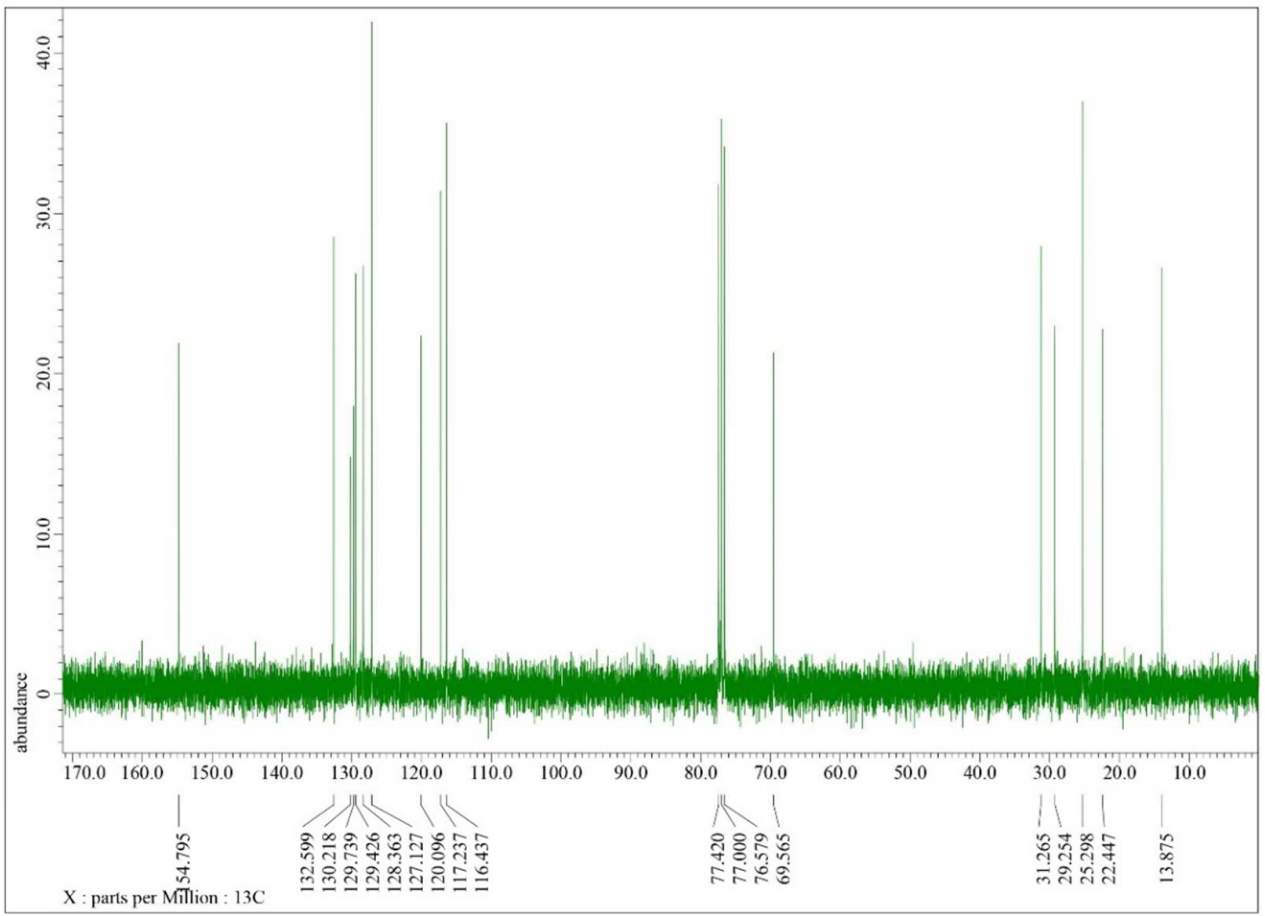

Figure S3. ${ }^{13} \mathrm{C}$ NMR spectra of $(\boldsymbol{R})-\mathbf{1}$ (whole).

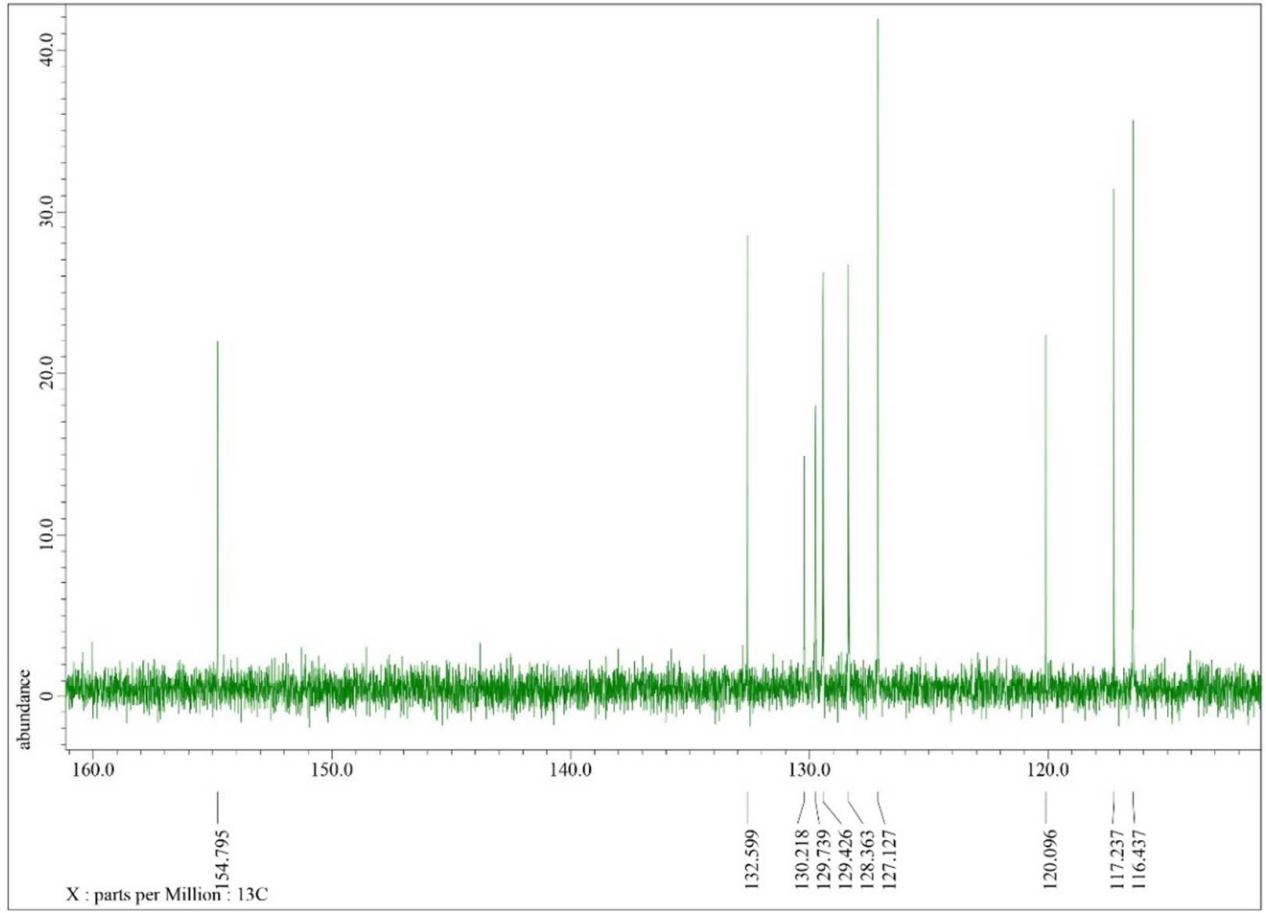

Figure S4. ${ }^{13} \mathrm{C}$ NMR spectra of $(\boldsymbol{R})-\mathbf{1}(162-110 \mathrm{ppm})$. 


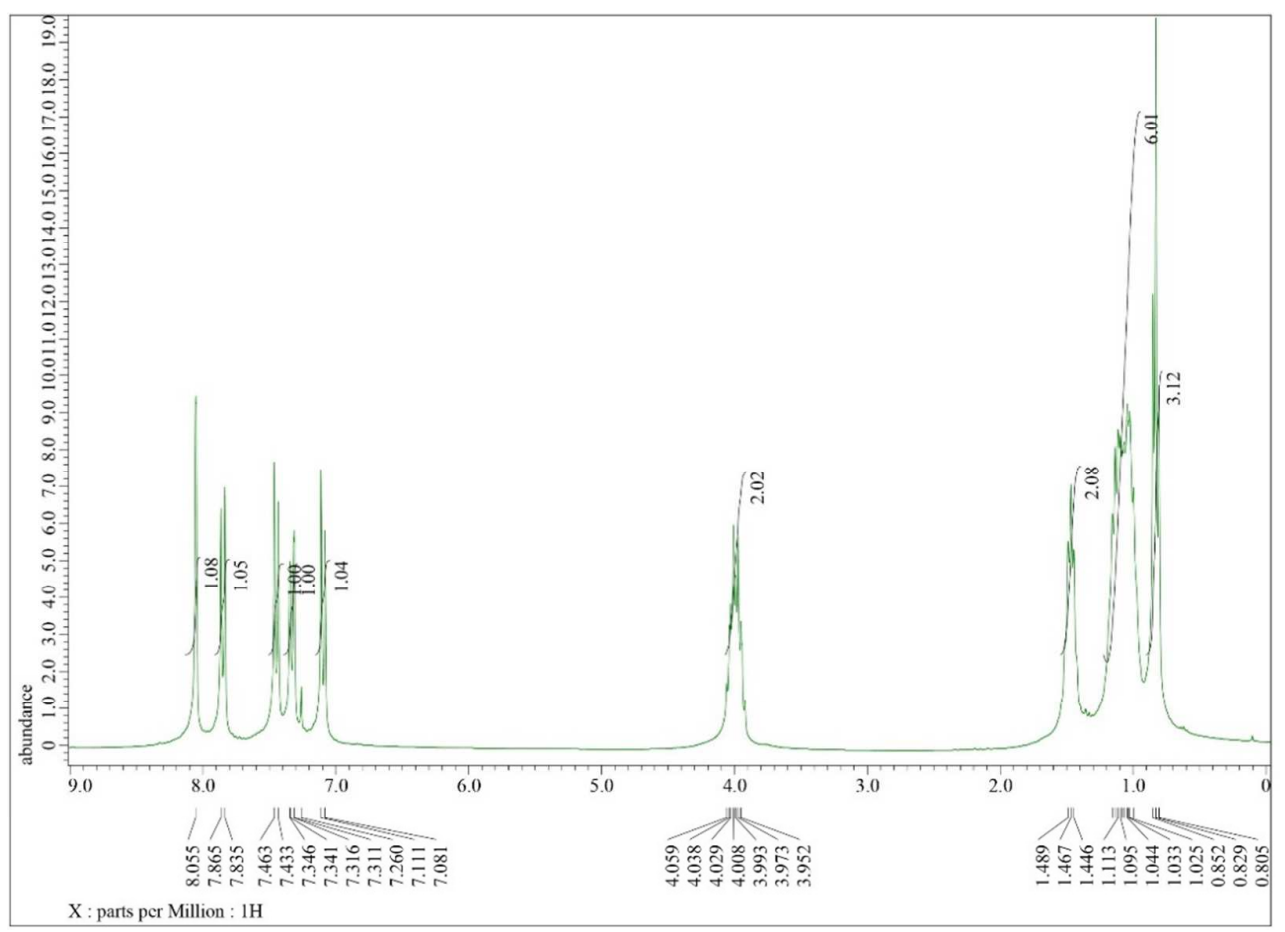

Figure S5. ${ }^{1} \mathrm{H}$ NMR spectra of $(\boldsymbol{S})-\mathbf{1}$ (whole).

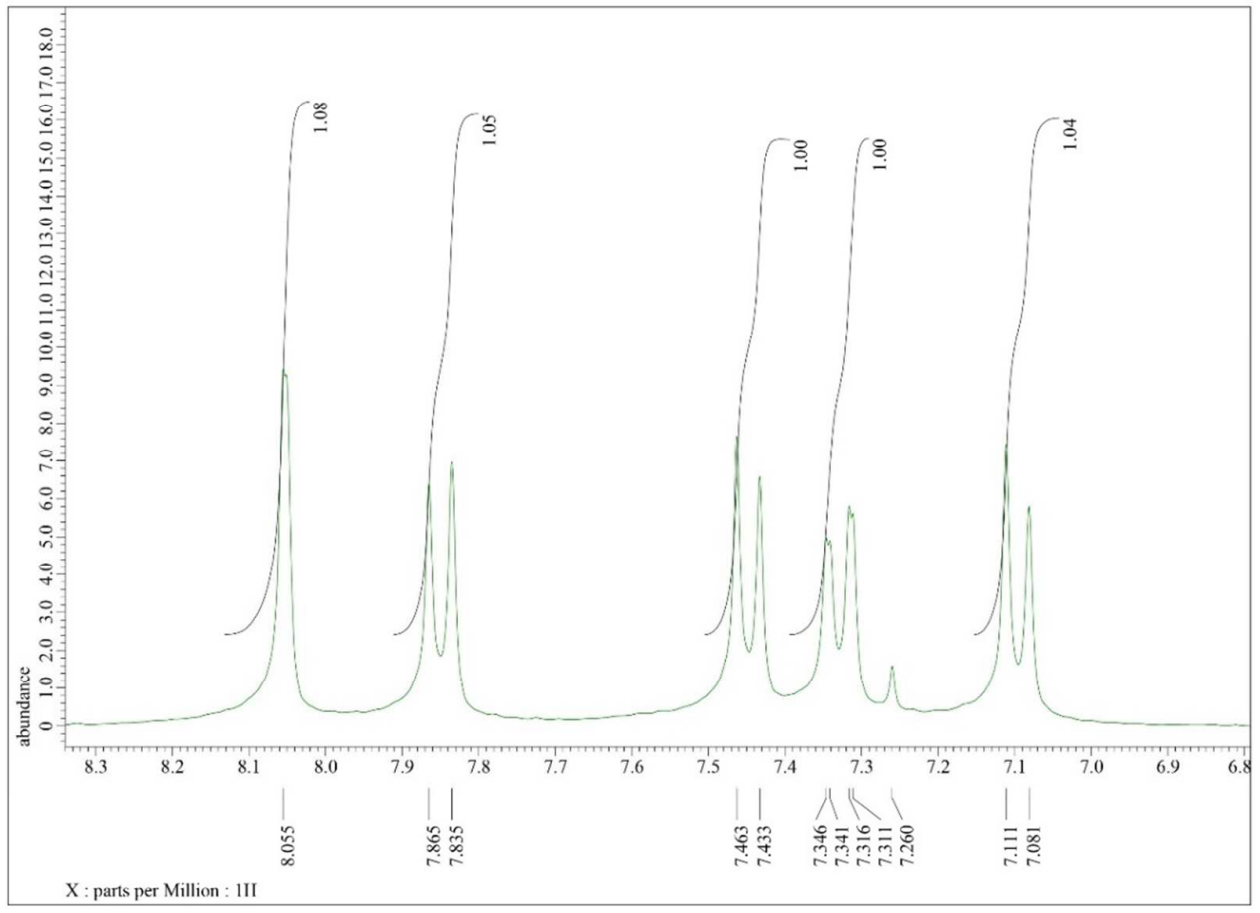

Figure S6. ${ }^{1} \mathrm{H}$ NMR spectra of $(\boldsymbol{S})-\mathbf{1}(8.3-6.8 \mathrm{ppm})$. 


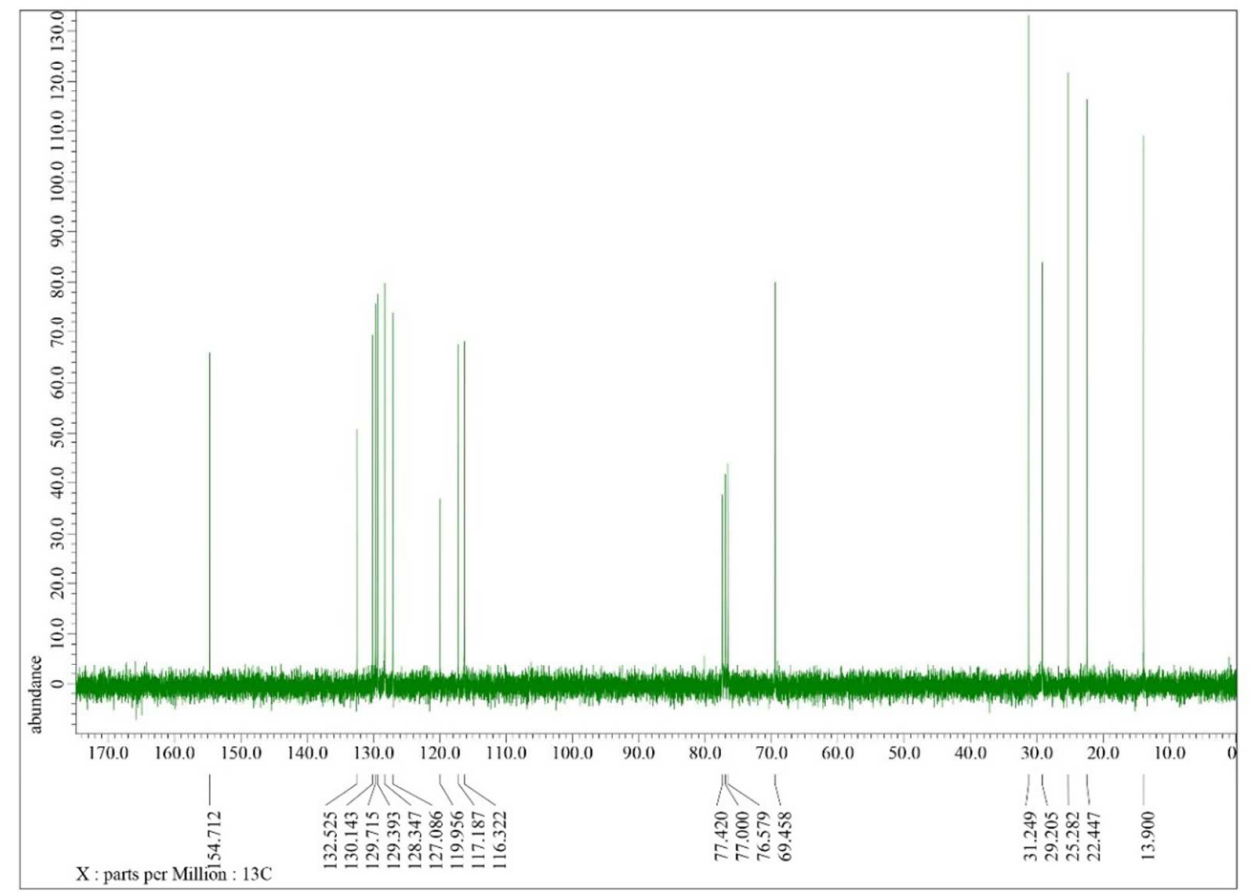

Figure S7. ${ }^{13} \mathrm{C}$ NMR spectra of $(\boldsymbol{S})-\mathbf{1}$ (whole).

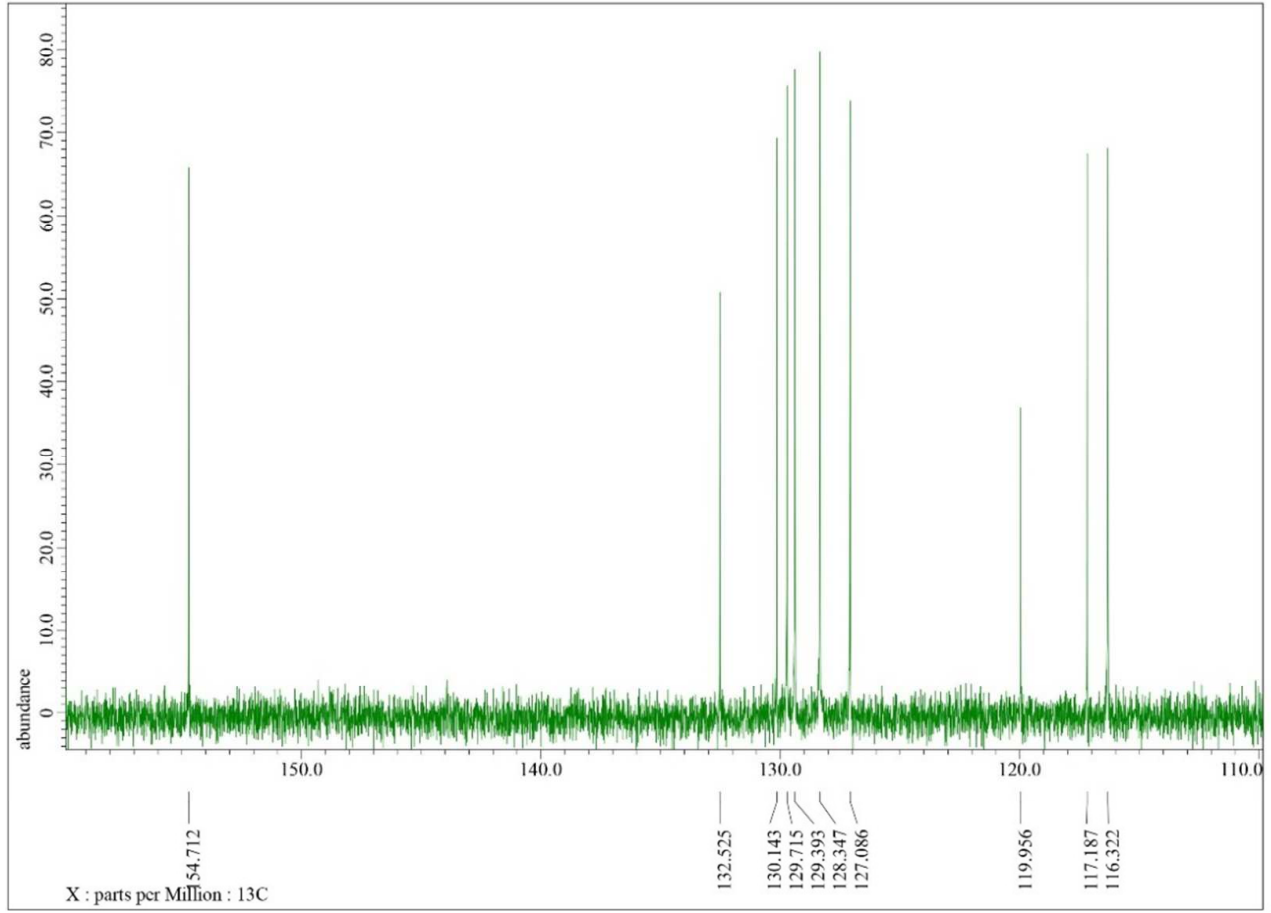

Figure S8. ${ }^{13} \mathrm{C}$ NMR spectra of $(\boldsymbol{S})-\mathbf{1}(160-110 \mathrm{ppm})$. 


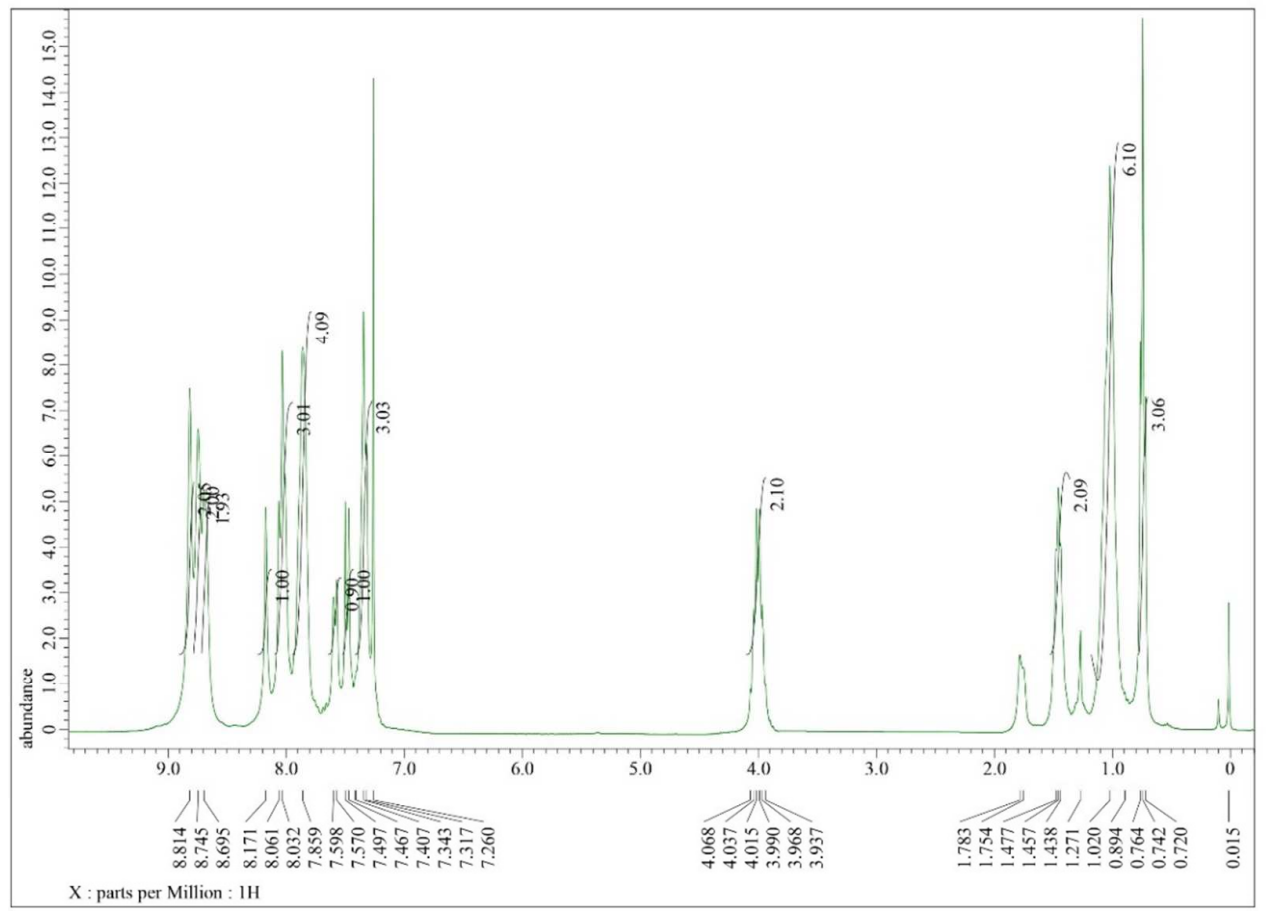

Figure S9. ${ }^{1}$ H NMR spectra of (R)-L1 (whole).

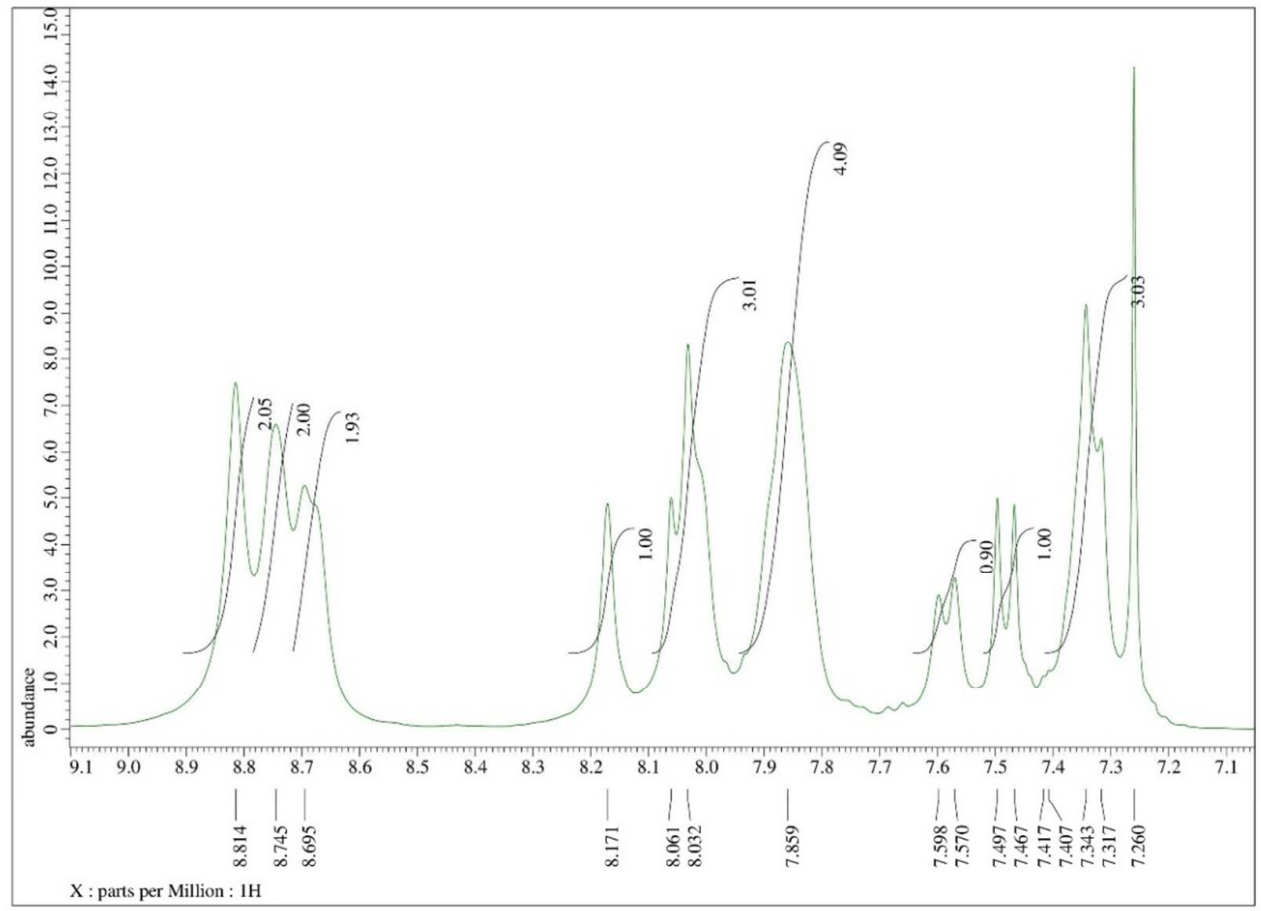

Figure S10. ${ }^{1} \mathrm{H}$ NMR spectra of $(\boldsymbol{R})$-L1 (9.1 - $\left.7.1 \mathrm{ppm}\right)$. 


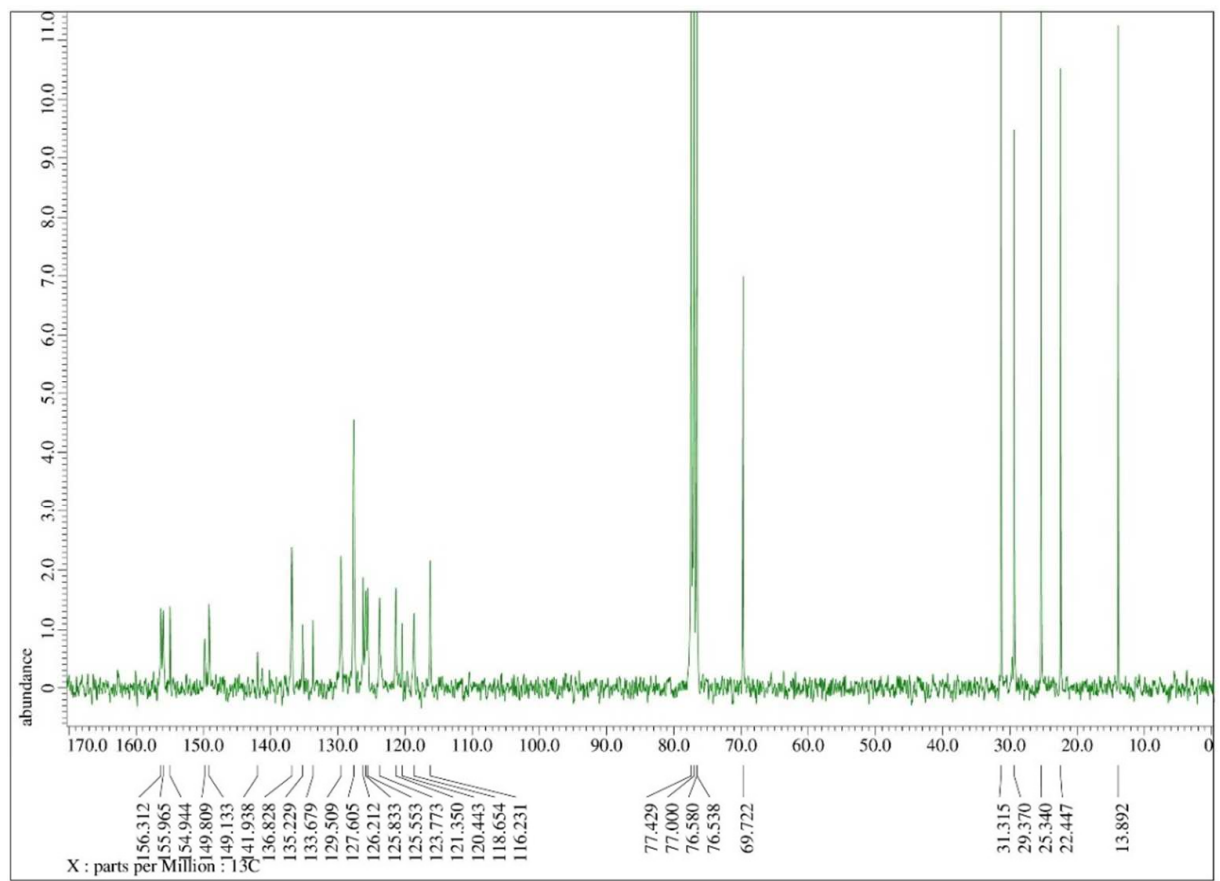

Figure S11. ${ }^{13} \mathrm{C}$ NMR spectra of $(\boldsymbol{R})$-L1 (whole).

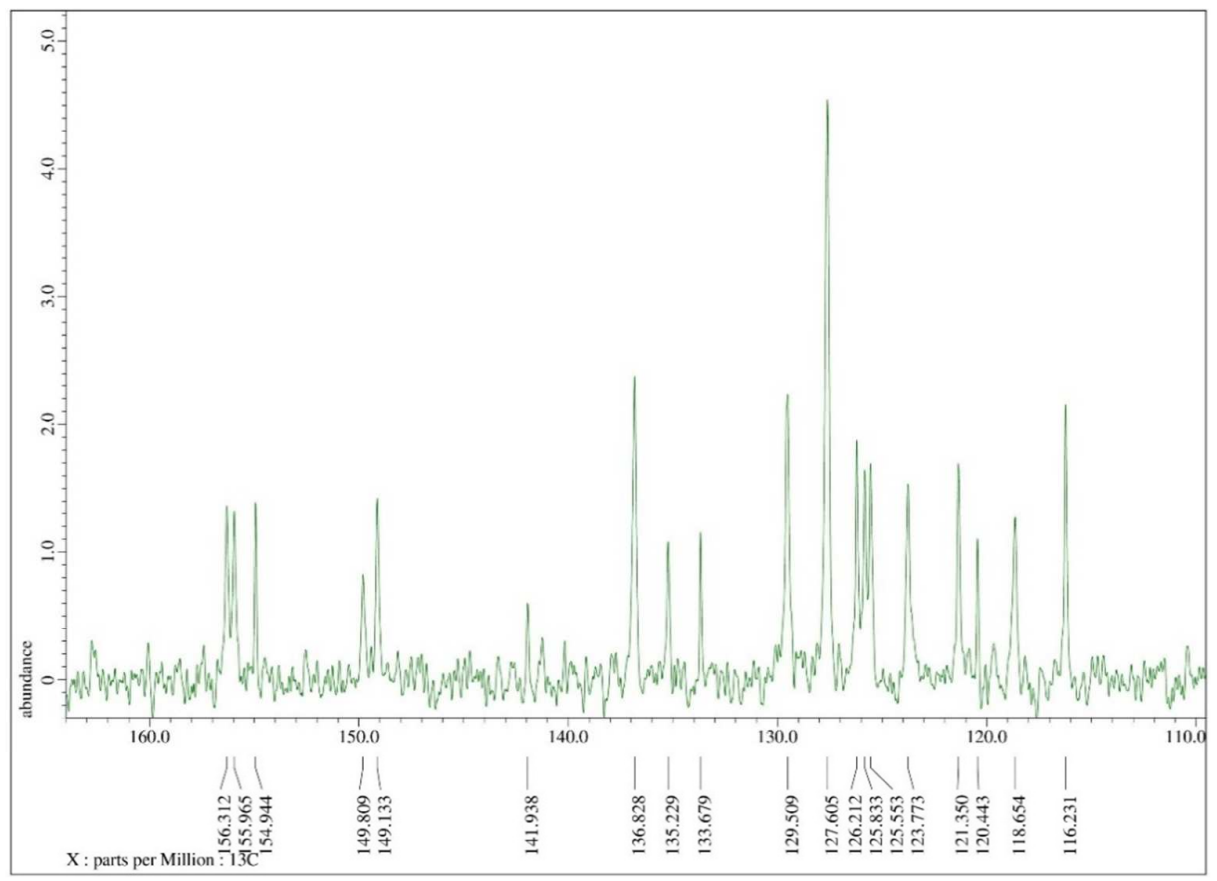

Figure S12. ${ }^{13} \mathrm{C}$ NMR spectra of $(\boldsymbol{R})-\mathbf{L} 1(165-110 \mathrm{ppm})$. 


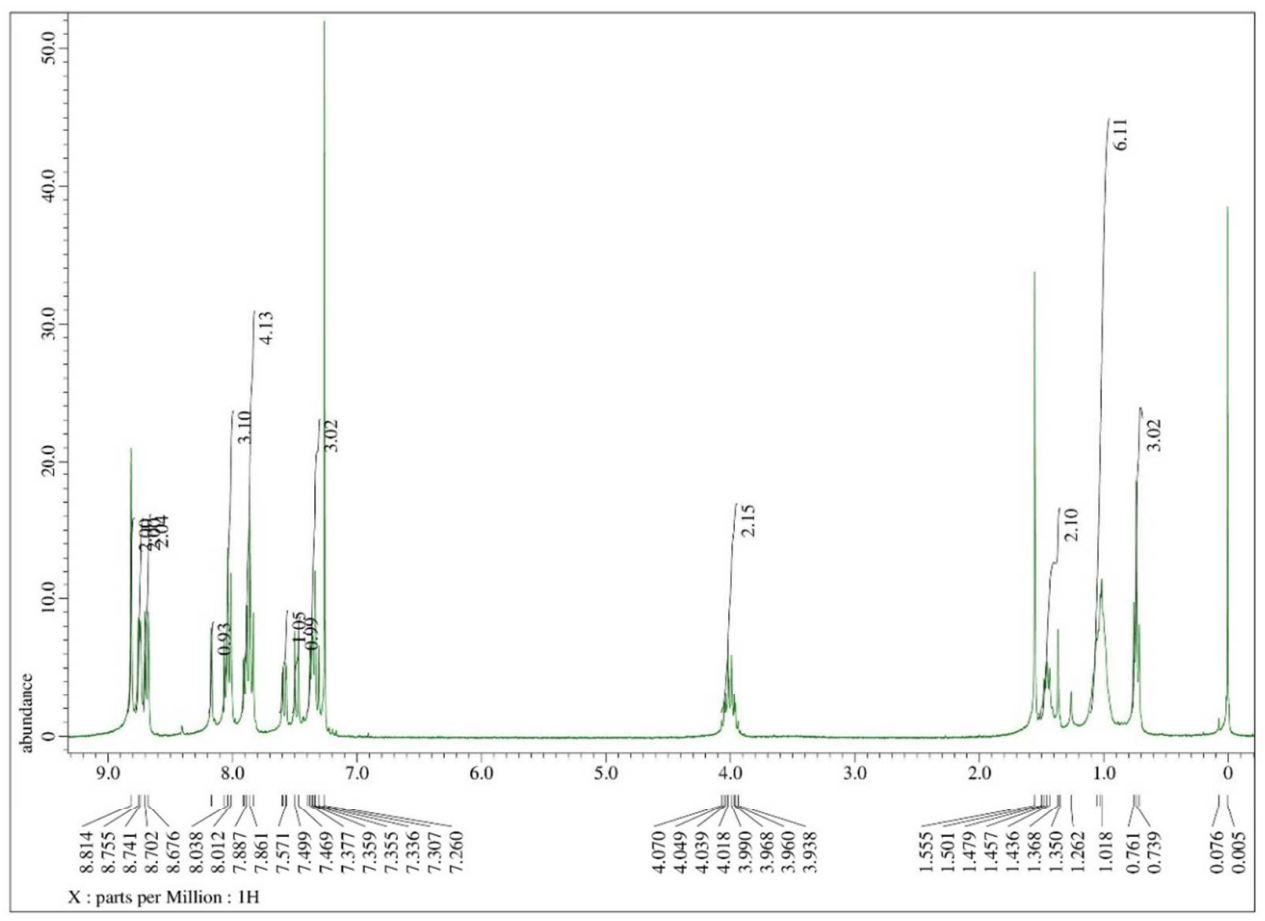

Figure S13. ${ }^{1}$ H NMR spectra of (S)-L1 (whole).

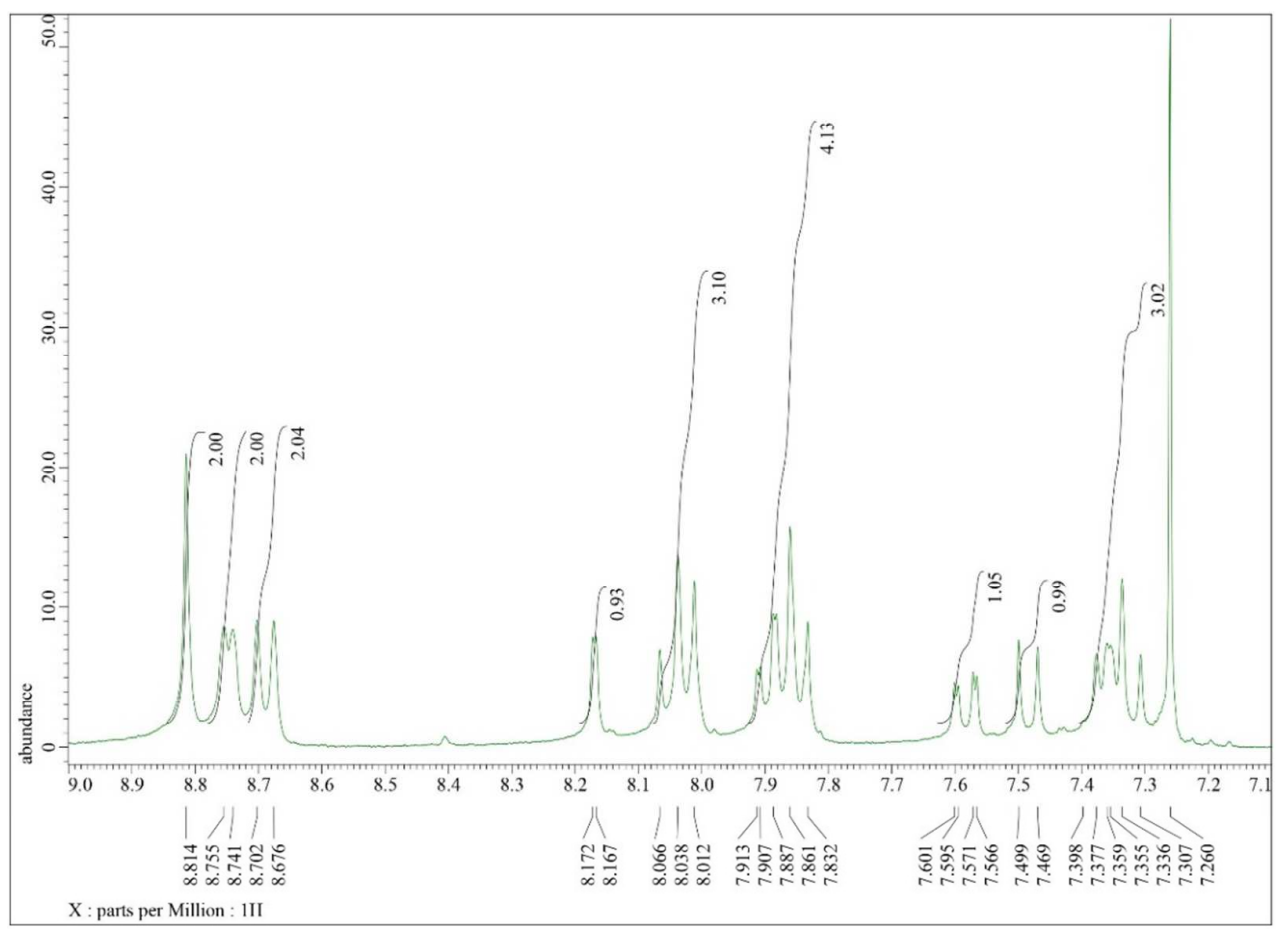

Figure S14. ${ }^{1} \mathrm{H}$ NMR spectra of $(\boldsymbol{S})-\mathbf{L 1}(9.0-7.1 \mathrm{ppm})$. 


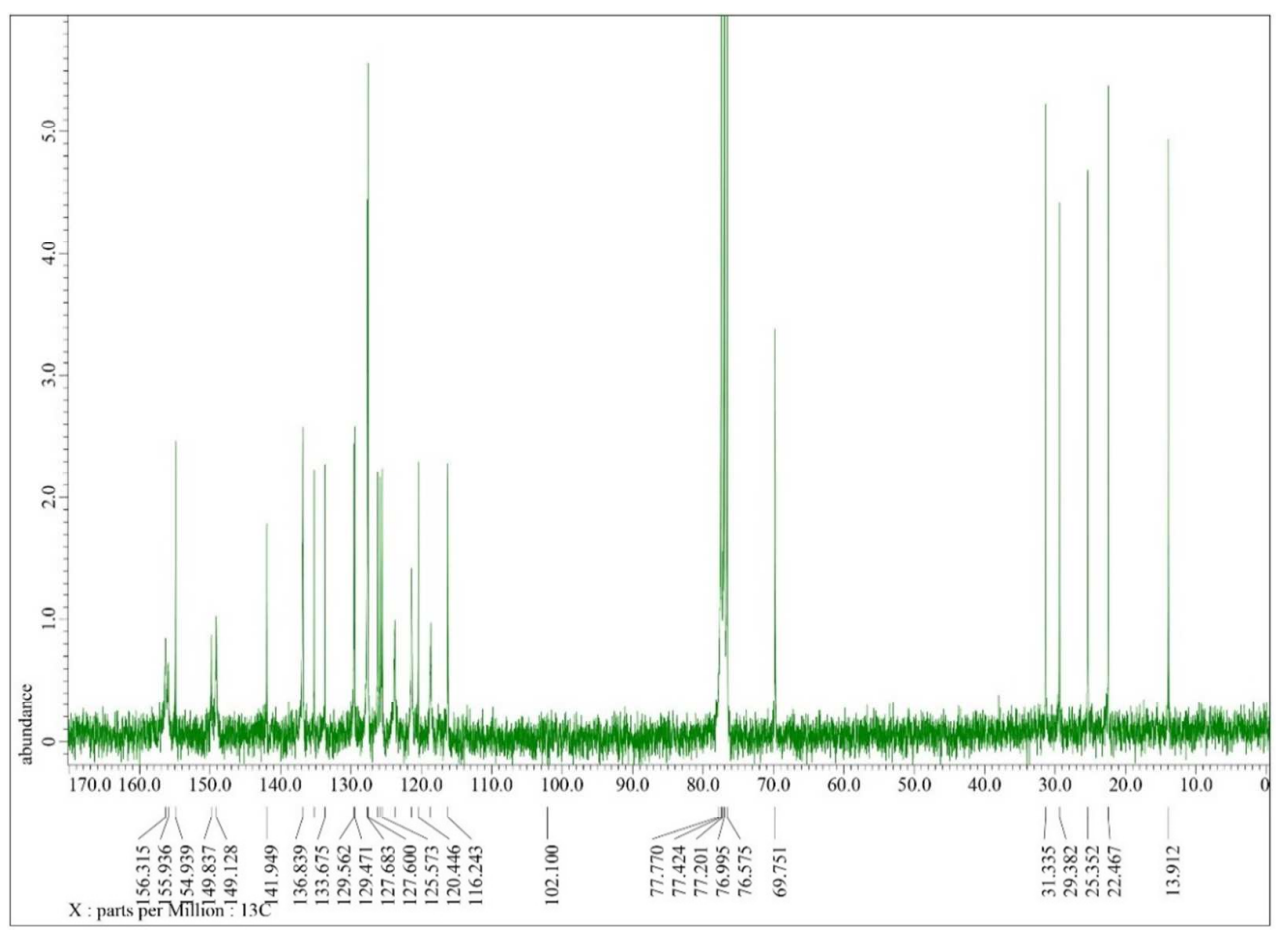

Figure S15. ${ }^{13} \mathrm{C}$ NMR spectra of $(\boldsymbol{S})$-L1 (whole).

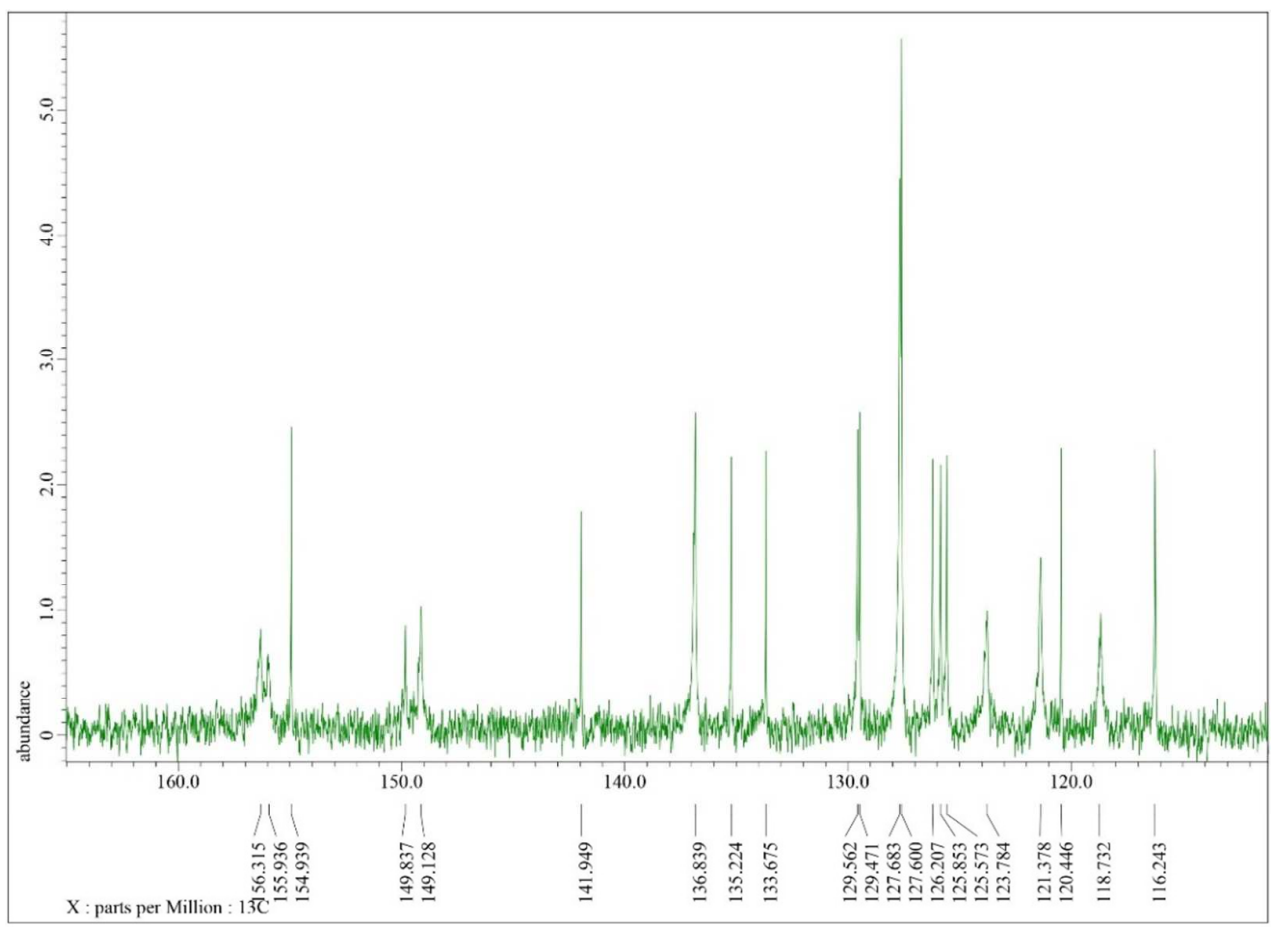

Figure S16. ${ }^{13} \mathrm{C}$ NMR spectra of $(\boldsymbol{S})-\mathbf{L 1}(165-110 \mathrm{ppm})$. 

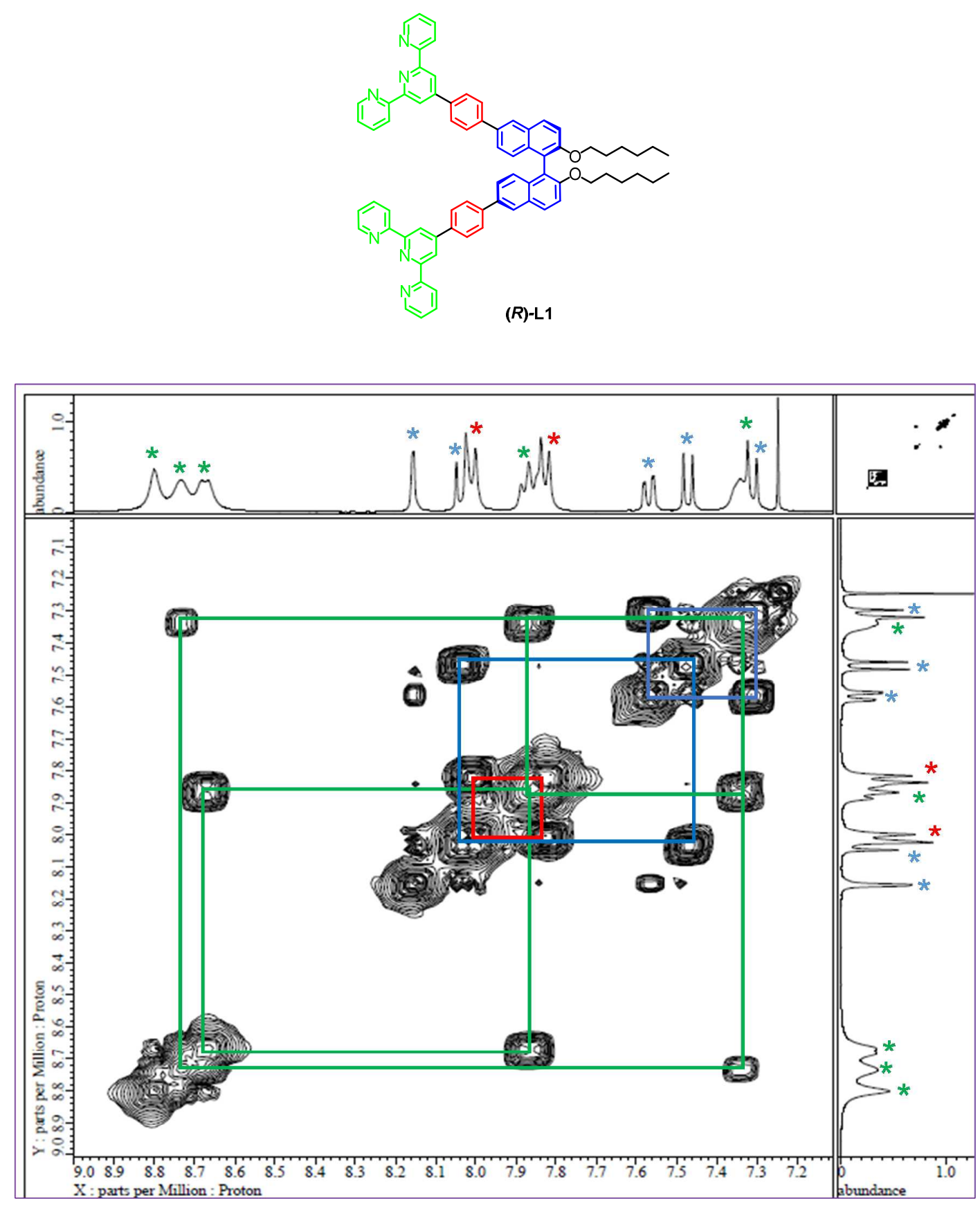

Figure S17. ${ }^{1} \mathrm{H}-{ }^{1} \mathrm{H}$ COSY NMR spectra of $(\boldsymbol{R})-\mathbf{L} 1$. 


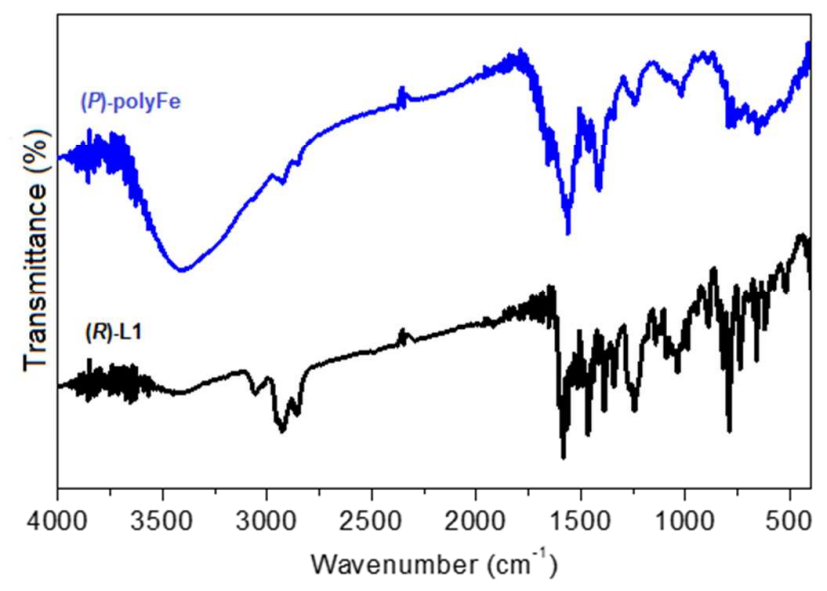

Figure S18. FTIR spectra of $(R)-L 1$ and $(P)$-polyFe.

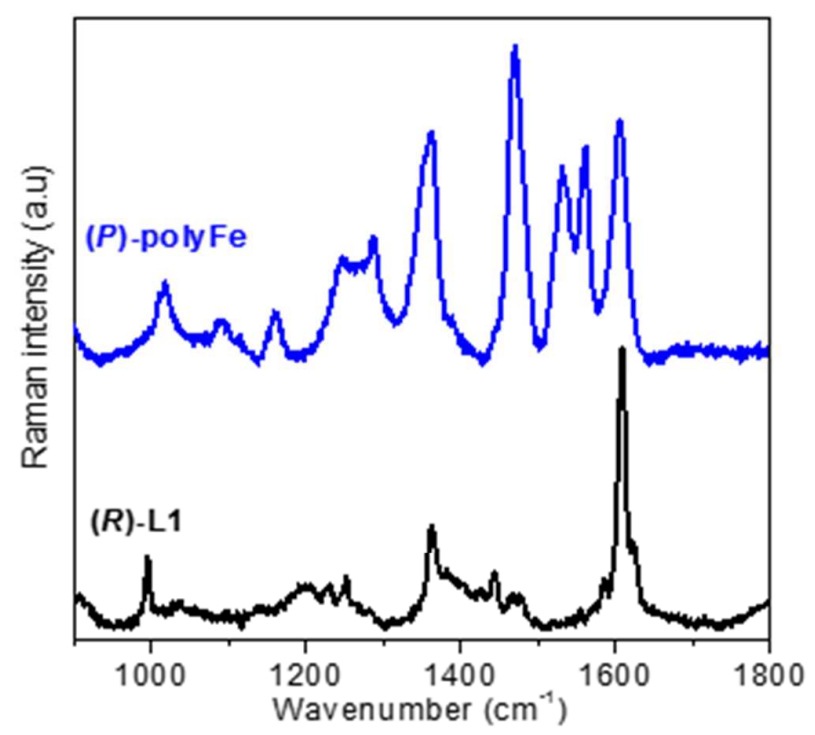

Figure S19. Raman spectra of (R)-L1 and (P)-polyFe. 


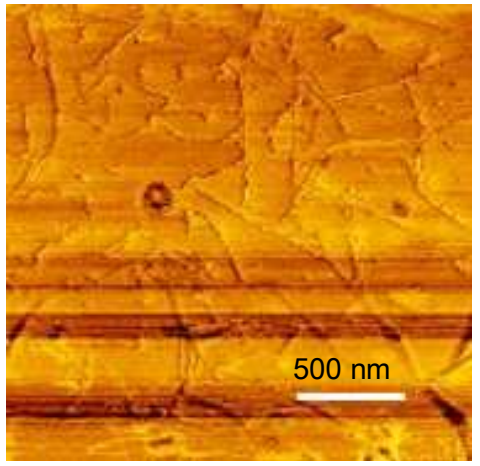

Figure S20. An AFM image of ct-DNA (B-form), (concentration $=50 \mu \mathrm{M})$.
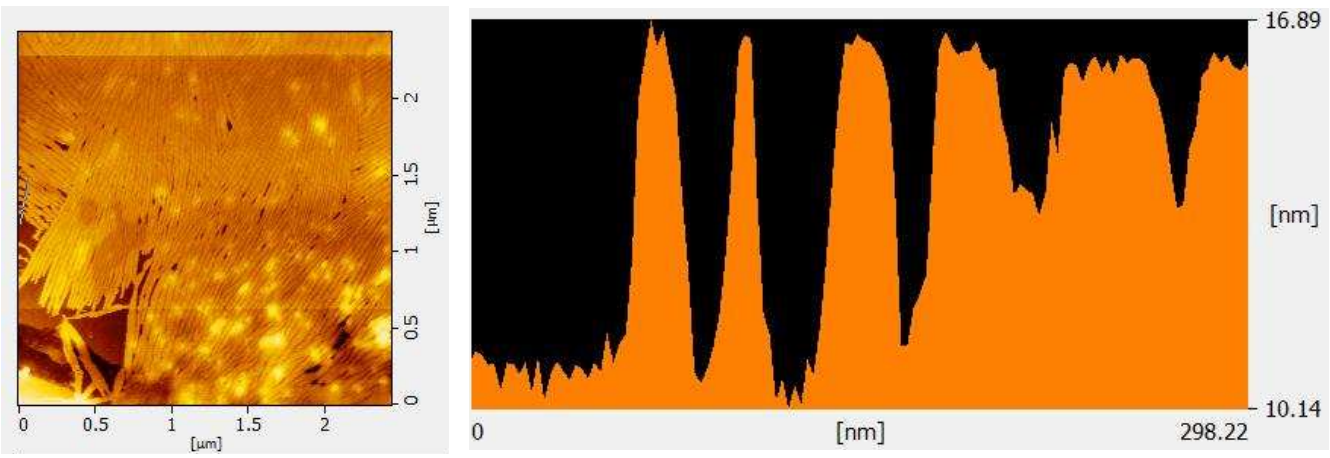

Figure S21. Height profile of ct-DNA (B-form)-( $P$--polyFe conjugates. 